\title{
КОМПЬЮТЕРНОЕ МОДЕЛИРОВАНИЕ КАК ОСНОВА РАЗВИТИЯ НАУЧНО-ИССЛЕДОВАТЕЛЬСКОЙ КОМПЕТЕНЦИИ СТУДЕНТОВ
}

\section{Тюльпинова Н.В.}

Брянский государственный технический университет,

г. Брянск, Российская Федерация

Рассмотрены вопросы организачии учебных исследований с применением компьютерного моделирования. Представлены примеры постановки учебных исследований, реализуемых с применением компьютерного моделирования.

Ключевые слова: компьютерное моделирование; учебное исследование.

\section{COMPUTER MODELING AS A BASE OF DEVELOPMENT OF RESEARCH COMPETENCE OF STUDENTS}

\section{Tyulpinova N.V.}

Bryansk State Technical University, Bryansk, Russian Federation

The issues of educational research using methods of computer modeling is considered. Examples of educational research implemented with the use methods of computer modeling are presented.

Keywords: computer modeling; educational research.

На современном этапе развития системы высшего образования научно-исследовательская деятельность студентов приобретает все большую актуальность и превращается в один из основных компонентов профессиональной подготовки будущих инженеров, поскольку современные профессионалы должны не только уметь применять передовые технологии, но и создавать эти передовые 
технологии - сегодня существует потребность в специалистах с «опережающими» знаниями, способных формировать новые направления науки и промышленности. В этой связи особое значение приобретает компьютерное моделирование как основа развития научно-исследовательской компетенции студентов. Компьютерное моделирование на современном этапе должно стать одной из фундаментальных учебных дисциплин, что закреплено в проекте «Новые стратегии обучения инженеров с использованием сред визуального моделирования и открытых учебных платформ (InMotion)» [1], реализуемом международным консорциумом университетов. Основной целью данного проекта является продолжение реформы системы высшего инженерного образования для повышения качества образования и обучения в соответствии со стандартами и приоритетами Стратегической рамочной программы европейского сотрудничества в области образования и профессиональной подготовки. Проект «InMotion» предполагает переход от существующей системы образования, выпускающей инженеров-пользователей готовых компьютерных моделей, к новой системе, обеспечивающей подготовку инженеров-разработчиков принципиально новых и передовых компьютерных моделей.

В [2]-[14] опубликованы некоторые примеры машиностроительных задач, для решения которых использование компьютерного моделирования является целесообразным. Эти задачи представляют собой разновидность учебно-исследовательских задач, порождающих проблемные ситуации, для разрешения которых требуется экспериментирование с компьютерными моделями машиностроительных объектов.

Ниже перечислены основные этапы, рекомендуемые при организации и проведении учебного исследования на основе компьютерного моделирования: 1) формулировка цели и задач исследования; 2) изучение и концептуальное описание исследуемой системы; 3) определение адекватности концептуальной модели; 4) детализация и формализация принятой концепции; 5) выбор или разработка компьютерной программы и ее проверка; 6) верификация программной 
модели; 7) планирование экспериментов; 8) выполнение программы вычислительных экспериментов; 9) оценка и анализ результатов; 10) документирование результатов и принятие решений. Также необходимо отметить, что исследование систем посредством компьютерного моделирования представляет собой итерационный процесс, предполагающий не линейную последовательность работ, а цикл повторяющихся этапов анализа и синтеза вариантов модели

Результаты исследований, опубликованных в [2]-[14], могут быть положены в основу виртуальных учебно-исследовательских практикумов, используемых при подготовке будущих инженеров.

\section{Список литературы}

1. Новые стратегии обучения инженеров с использованием сред визуального моделирования и открытых учебных платформ / Зупанчич Б., Мьюзик Г., Новопашенный И.В., Уркия А., Рыжов В.А., Сениченков Ю.Б., Соколов Б.В., Шорников Ю.В. // Труды Восьмой всероссийской научно-практической конференции «Имитационное моделирование. Теория и практика» (ИММОД-2017). СПб.: Изд-во BBM, 2017. С. 37-45.

2. Определение равномерно изнашивающейся формы шлифовального круга при работе периферией / Овсянников Д.С., под рук-вом доц. Тюльпиновой Н.В. // Материалы 65-й студенческой научной конференции: посвящ. 65-летию Великой Победы. Брянск: БГТУ, 2010. С. 141.

3. Программный модуль для расчета формы равномерного износа шлифовальных кругов / Малиновский И.И., под рук-вом доц. Тюльпиновой Н.В. // Материалы 65-й студенческой научной конференции: посвящ. 65-летию Великой Победы. Брянск: БГТУ, 2010. С. 201-202.

4. Трехмерное моделирование слоя, срезаемого абразивным зерном при шлифовании / Костоглотова И.И., под рук-вом доц. Тюльпиновой Н.В. // Материалы 66-й студенческой научной конференции. Брянск: БГТУ, 2011. С. 92-93.

5. Компьютерное моделирование процессов резания / Болтовский С.В., под рук-вом доц. Тюльпиновой Н.В. // Материалы 67-й студенческой научной конференции. Брянск: БГТУ, 2012. С. 73. 
6. Трехмерное моделирование процесса алмазного шлифования / Костоглотова И.И., под рук-вом доц. Тюльпиновой Н.В. // Материалы 67-й студенческой научной конференции. Брянск: БГТУ, 2012. С. 77.

7. Разработка автоматизированной системы проектирования круглых фасонных резцов / Серенко Р.А., под рук-вом доц. Тюльпиновой Н.В. // Материалы 68-й студенческой научной конференции. Брянск: БГТУ, 2013. С. 95-96.

8. Разработка автоматизированной системы исследования влияния параметров станочного зацепления на геометрию зубьев зубчатых колес / Арутюнян Р.А., под рук. доц. Тюльпиновой Н.В. // Материалы 69-й студенческой научной конференции. Брянск: БГТУ, 2014. С. 66-67.

9. Параметрическое твердотельное моделирование тел вращения на примере вала в системе T-FLEX CAD / Арутюнян Р.А., под рук-вом доц. Тюльпиновой Н.В. // Материалы 71-й студенческой научной конференции. Брянск: БГТУ, 2016. С. 156-158.

10. Параметрическое твердотельное моделирование корпусных деталей редукторов в системе T-FLEX CAD / Курилов А.В., под рук-вом доц. Тюльпиновой Н.В. // Материалы 71-й студенческой научной конференции. Брянск: БГТУ, 2016. С. 193-195.

11. Анимация сборочных чертежей в системе T-FLEX CAD / Шауро Д.Н., под рук-вом доц. Тюльпиновой Н.В. // Материалы 71-й студенческой научной конференции. Брянск: БГТУ, 2016. С. 234-235.

12. Разработка автоматизированной системы проектирования резьбонакатных роликов / Шауро Д.Н., под рук-вом доц. Тюльпиновой Н.В. // Материалы 71-й студенческой научной конференции. Брянск: БГТУ, 2016. С. 236-238.

13. Анализ возможностей и перспектив применения современных координатно-измерительных технологий / Шауро Д.Н., под рук-вом доц. Тюльпиновой Н.В. // Материалы 72-й студенческой научной конференции. Брянск: БГТУ, 2017. С. 216-218.

14. Разработка параметрической оптимизационной модели роликового натягивающего устройства / Сапрыко А.А., под рук-вом доц. Тюльпиновой Н.В. // Материалы 73-й студенческой научной конференции. Брянск: БГТУ, 2018. С. 189-191. 


\section{References}

1. Novye strategii obucheniya inzhenerov s ispol'zovaniem sred vizual'nogo modelirovaniya i otkrytykh uchebnykh platform / Zupanchich B., M'yuzik G., Novopashennyy I.V., Urkiya A., Ryzhov V.A., Senichenkov Yu.B., Sokolov B.V., Shornikov Yu.V. // Trudy Vos'moy vserossiyskoy nauchno-prakticheskoy konferentsii «Imitatsionnoe modelirovanie. Teoriya i praktika» (IMMOD-2017). SPb.: Izd-vo VVM, 2017. S. 37-45.

2. Opredelenie ravnomerno iznashivayushcheysya formy shlifoval'nogo kruga pri rabote periferiey / Ovsyannikov D.S., pod ruk-vom dots. Tyul'pino-voy N.V. // Materialy 65-y studencheskoy nauchnoy konferentsii: posvyashch. 65-letiyu Velikoy Pobedy. Bryansk: BGTU, 2010. S. 141.

3. Programmnyy modul' dlya rascheta formy ravnomernogo iznosa shlifoval'nykh krugov / Malinovskiy I.I., pod ruk-vom dots. Tyul'pinovoy N.V. // Materialy 65-y studencheskoy nauchnoy konferentsii: posvyashch. 65-letiyu Velikoy Pobedy. Bryansk: BGTU, 2010. S. 201-202.

4. Trekhmernoe modelirovanie sloya, srezaemogo abrazivnym zernom pri shlifovanii / Kostoglotova I.I., pod ruk-vom dots. Tyul'pinovoy N.V. // Materialy 66-y studencheskoy nauchnoy konferentsii. Bryansk: BGTU, 2011. S. 92-93.

5. Komp'yuternoe modelirovanie protsessov rezaniya / Boltovskiy S.V., pod ruk-vom dots. Tyul'pinovoy N.V. // Materialy 67-y studencheskoy nauchnoy konferentsii. Bryansk: BGTU, 2012. S. 73.

6. Trekhmernoe modelirovanie protsessa almaznogo shlifovaniya / Kostoglo-tova I.I., pod ruk-vom dots. Tyul'pinovoy N.V. // Materialy 67-y studen-cheskoy nauchnoy konferentsii. Bryansk: BGTU, 2012. S. 77.

7. Razrabotka avtomatizirovannoy sistemy proektirovaniya kruglykh fa-sonnykh reztsov / Serenko R.A., pod ruk-vom dots. Tyul'pinovoy N.V. // Ma-terialy 68-y studencheskoy nauchnoy konferentsii. Bryansk: BGTU, 2013. S. 95-96.

8. Razrabotka avtomatizirovannoy sistemy issledovaniya vliyaniya parametrov stanochnogo zatsepleniya na geometriyu zub'ev zubchatykh koles / Arutyu-nyan R.A., pod ruk-vom dots. Tyul'pinovoy N.V. // Materialy 69-y studen-cheskoy nauchnoy konferentsii. Bryansk: BGTU, 2014. S. 66-67. 
9. Parametricheskoe tverdotel'noe modelirovanie tel vrashcheniya na primere vala v sisteme T-FLEX CAD / Arutyunyan R.A., pod ruk-vom dots. Tyul'pi-novoy N.V. // Materialy 71-y studencheskoy nauchnoy konferentsii. Bryansk: BGTU, 2016. S. 156-158.

10. Parametricheskoe tverdotel'noe modelirovanie korpusnykh detaley reduktorov v sisteme T-FLEX CAD / Kurilov A.V., pod ruk-vom dots. Tyul'pinovoy N.V. // Materialy 71-y studencheskoy nauchnoy konferentsii. Bryansk: BGTU, 2016. S. 193-195.

11. Animatsiya sborochnykh chertezhey v sisteme T-FLEX CAD / Shauro D.N., pod ruk-vom dots. Tyul'pinovoy N.V. // Materialy 71-y studencheskoy nauchnoy konferentsii. Bryansk: BGTU, 2016. S. 234-235.

12. Razrabotka avtomatizirovannoy sistemy proektirovaniya rez'bo-nakatnykh rolikov / Shauro D.N., pod ruk-vom dots. Tyul'pinovoy N.V. // Materialy 71-y studencheskoy nauchnoy konferentsii. Bryansk: BGTU, 2016. S. 236-238.

13. Analiz vozmozhnostey i perspektiv primeneniya sovremennykh koordi-natno-izmeritel'nykh tekhnologiy / Shauro D.N., pod ruk-vom dots. Tyul'-pinovoy N.V. // Materialy 72-y studencheskoy nauchnoy konferentsii. Bryansk: BGTU, 2017. S. 216-218.

14. Razrabotka parametricheskoy optimizatsionnoy modeli rolikovogo natyagivayushchego ustroystva / Sapryko A.A., pod ruk-vom dots. Tyul'pino-voy N.V. // Materialy 73-y studencheskoy nauchnoy konferentsii. Bryansk: BGTU, 2018. S. 189-191. 